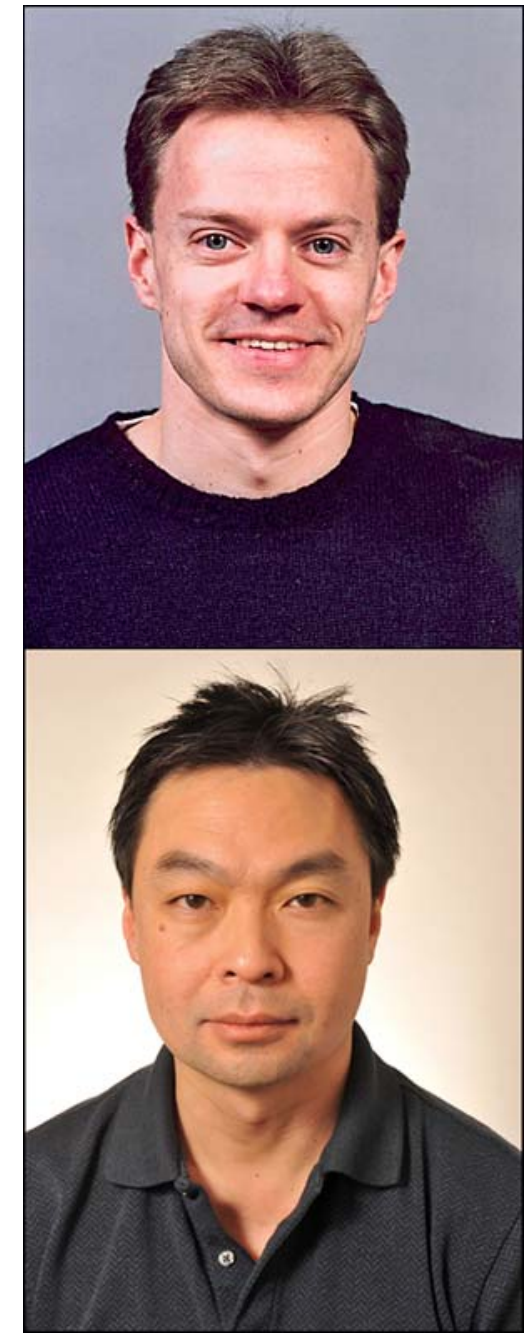

Joseph Hidler, PhD; Peter S. Lum, PhD

\section{The road ahead for rehabilitation robotics}

During President Barack Obama's acceptance speech on the evening of his 2008 Presidential election victory, he spoke about Ann Nixon Cooper, a 106-year-old woman who had voted in her first election. He spoke of all the great things she had seen in her long life, then stated, "If my daughters should be so lucky to live as long as Ann Nixon Cooper, what change will they see, what progress will we have made?" The same sentiment can be asked about rehabilitation robotic devices. As we move into the second decade of the 21 st century, we should pause and ask a very important question: What is the future of rehabilitation robotic devices? Will these devices become commonplace in every hospital and rehabilitation clinic or will they become things of the past like so many other promising technologies? Will we, as a rehabilitation community, break down the barriers between therapists and engineers and work together or will there be continued division? As two scientists and engineers who have worked in the area of rehabilitation robotics for over a decade, we are encouraged by the future of the field but concerned that there is not enough dialog regarding how we should move forward. We are hopeful that this special issue of the Journal of Rehabilitation Research and Development dedicated to rehabilitation robotics will stimulate discussion and thought on these important questions.

Understanding the future of rehabilitation robotics is quite complex, because we must first answer a number of related questions. For example, (1) What is the goal of the robot? (2) What are the barriers to the clinical acceptance of robotic devices in rehabilitation? (3) What should future robotic devices look like; should they be more portable and perhaps stay with the patient as they transition from inpatient care to home? While these questions are difficult to answer, they are critical in shaping the future of the field. Too often we find that engineers come up with ideas for new devices, yet they have not worked with clinicians enough to adequately understand key goals for their systems, how the systems should interact with the patient, and ultimately, how the systems will be accepted in a rehabilitation clinic. While these questions are broad and require more than a short editorial to answer, we wanted to touch on them to begin a dialogue.

We often get so caught up in the technology that we overlook the obvious. For instance, what is the goal of the robot and what advantages does the robot offer the patient and/or therapist? We argue that robots should be developed to assist with therapeutic activities that are difficult or impossible for the therapist to administer alone. For example, attempting overground gait and balance training in a patient with both heavy weight and low function is difficult and unsafe for the average therapist. Devices such as ZeroG (Hidler et al. [1]) can alleviate a portion of the patient's body weight to compensate for weakness in lower limbs and can safeguard him or her against 
falling. The goals of such devices are to assist the therapist so that they may safely train patients in standing, walking, and performing balance activities early after injuries. These tasks are difficult for therapists; however, with robotic technologies, they are possible. Unlike treating gait and balance, in which safety is a principal concern, upper-limb therapies present other unique challenges. For example, delivering intensive hand therapy is often difficult in patients following stroke and traumatic brain injury since these patients may have tone and spasticity that results in a fist-like posture. Devices such as HEXORR [2] and HandSOME [3] can assist patients as they practice opening and closing their hands, a task that is quite difficult for a single therapist to assist with. Overall, we believe the goal of rehabilitation robotic devices should be to assist therapists in performing the types of activities and exercises they believe give their patients the best chance of a functional recovery.

The examples given earlier demonstrate that robotic devices can fill the gaps in rehabilitation where it is difficult and/or unsafe for a therapist to attempt to deliver a particular type of therapy. This should be a key goal of all rehabilitation robotic technologies, yet is often overlooked because engineers do not talk with clinicians during the most important stage of the technology development cycle: the planning stage. Attendees of the International Conference on Rehabilitation Robotics (ICORR) can quickly see the problem. First, very few clinicians attend the meeting, yet these are the end-users of rehabilitation robots. Meetings such as ICORR, the International Conference on Robotics and Automation, and other technical symposia should be promoted in the clinical community so that clinicians attend and provide critical feedback to the engineers. Second, some newer devices are incredibly complicated, both from an engineering and a usability point of view. In the United States, a typical rehabilitation treatment session is 1 hour long, and therapists are often required to treat multiple patients during that time. If a device requires 2 hours to set up, the likelihood it will ever be adopted in the clinical community is very small. It seems to us that "simple-to-use" devices are more likely to be adopted by the clinical community than those that have long set-up times or require multiple therapists and/or aides to use. If patients could begin therapy sessions quickly, this would translate into more time for repetitions and activities and thus, greater functional outcomes. Unfortunately, easy-touse does not necessarily translate into low cost. In fact, sometimes being able to deliver easy-to-use, highly flexible systems results in substantial costs. Ultimately, for devices to gain widespread acceptance in small rehabilitation clinics, the costs of these systems must come down.

The rehabilitation community as a whole needs to think about how to deliver cost-effective therapy in the future and what that therapy should look like. That is, in the current rehabilitation model, patients who experience a neurological injury (i.e., stroke, traumatic brain injury) will spend about 1 month as an inpatient in an acute rehabilitation hospital and then spend a few more months doing physical therapy on an outpatient basis. At that point, healthcare providers often stop paying for continued treatment and in their mind, the neurological injury "episode" is considered complete. But isn't this a naïve way of looking at the problem? Why do we approach rehabilitation in these people as temporary and not as a lifelong endeavor? Most people go to the gym all their lives to maintain a certain level of fitness and well-being. Why shouldn't we see therapy, particularly after major neurological injuries, as something that these patients should do for the rest of their lives? For those fortunate enough to experience significant gains in function, perhaps the therapy will transition more toward exercise. Rehabilitation should not be thought of as an activity people do for a short amount of time after they experience a major neurological injury but instead as a permanent activity they will continue for their entire life. Even extending the rehabilitation cycle to 1 year postinjury would be an important first step.

Assuming that this philosophy of extended rehabilitation, or perhaps lifelong rehabilitation, is one day adopted, the U.S. healthcare system could never afford the costs associated with it using the current model of care. Perhaps this is a void that robotic devices could fill. What if we could develop costeffective robots that could be used both in acute rehabilitation hospitals and at home by patients so that 
they could continue their therapy? Telemedicine and telerehabilitation are gaining momentum, so it is not inconceivable that we could build remote monitoring and easy-to-use features into rehabilitation devices so that therapists could work with patients at home [45]. This would allow patients to continue their therapy beyond the typical number of sessions most healthcare systems currently allow and even motivate patients who know that their activities can be monitored remotely by their doctor and therapist.

The road ahead for rehabilitation robotic devices is uncertain but promising. The field has come a long way over the last decade but we must now pause, reflect, and carefully consider the direction we should go. In this single-topic issue dedicated to rehabilitation robotics, we have assembled an outstanding collection of articles that introduce, review, and study various upper- and lower-limb robotic technologies. Tefertiller et al. provide a much-welcome clinical perspective with a comprehensive review of the evidence to date for the efficacy of robotic devices for lowerlimb therapy [6]. The latest in overground gait training systems is represented in this issue with an article on ZeroG [1]. Three articles tackle the critical issue of determining the most appropriate control algorithms and human-machine interfaces. Brokaw et al. describe a novel joint-based algorithm for training functional activities with the ARMin robot [7], and Acosta et al. show that while video games can provide a motivational interface, they will be most effective if designed to target specific impairments [8]. While adaptive control algorithms are under development based on actual task performance, Koenig et al. demonstrate the feasibility of real-time estimation of psychological state (i.e., motivation, stress level, attention), which can be used to optimally grade task difficulty [9]. Robotic therapies that can be delivered acutely may have the largest effect on function, but studies in this population are relatively rare so we are very pleased to include two articles on this topic. Masiero et al. review their work with the NeReBot for acute arm therapy after stroke [10], while Burgar et al. highlight the importance of providing higher therapy intensities (hours of therapy per day) in an acute stroke study using the MIME robot [11]. Three articles address the potential effect of robots as objective measurement tools. Scott and Dukelow present a rationale for how robots may improve rehabilitation practice by providing an objective means of quantifying motor, sensory, and cognitive impairments [12]. Peng et al. present their manual spasticity evaluator [13], and Roy et al. show that impedance-controlled robots such as the Anklebot can be used to assess single-session motor learning and retention [14]. In line with this editorial's emphasis on lifelong rehabilitation, two articles present robots with potential as takehome devices. Shorter et al. discuss their portable active ankle-foot orthosis, an untethered wearable device for rehabilitation of gait disorders [15], while Perry et al. address issues of usability and cost reduction with a variable pantograph mechanism that can be quickly reconfigured for different tasks or joints in the upper limb [16]. Finally, the potential use of robotic therapy in maintaining function in degenerative disorders has been largely unexplored. Wier et al. present a notable exception with their work in the multiple sclerosis population using the Lokomat [17].

\section{Joseph Hidler, PhD; ${ }^{1-2 *}$ Peter S. Lum, PhD ${ }^{2-3}$}

${ }^{1}$ Aretech, LLC, Ashburn, VA; ${ }^{2}$ National Rehabilitation Hospital, Washington, DC; ${ }^{3}$ Department of Biomedical Engineering, Catholic University of America, Washington, DC

*Email: hidler@,aretechllc.com

\section{REFERENCES}

1. Hidler J, Brennan D, Black I, Nichols D, Brady K, Nef T. ZeroG: Overground gait and balance training system. J Rehabil Res Dev. 2011;48(4):287-98. DOI:10.1682/JRRD.2010.05.0098

2. Schabowsky CN, Godfrey SB, Holley RJ, Lum PS. Development and pilot testing of HEXORR: Hand exoskeleton rehabilitation robot. J Neuroeng Rehabil. 2010;7:36. [PMID: 20667083]

DOI:10.1186/1743-0003-7-36

3. Brokaw EB, Holley RJ, Lum PS. Hand Spring Operated Movement Enhancer (HandSOME) device for hand rehabilitation after stroke. Conf Proc IEEE Eng Med Biol Soc. 2010;1:5867-70. [PMID: 21096926] 
4. McCue M, Fairman A, Pramuka M. Enhancing quality of life through telerehabilitation. Phys Med Rehabil Clin N Am. 2010;21(1):195-205. [PMID: 19951786] DOI:10.1016/j.pmr.2009.07.005

5. Kairy D, Lehoux P, Vincent C, Visintin M. A systematic review of clinical outcomes, clinical process, healthcare utilization and costs associated with telerehabilitation. Disabil Rehabil. 2009;31(6):427-47.

[PMID: 18720118] DOI:10.1080/09638280802062553

6. Tefertiller C, Pharo B, Evans N, Winchester P. Efficacy of rehabilitation robotics for walking training in neurological disorders: A review. J Rehabil Res Dev. 2011; 48(4):387-416. DOI:10.1682/JRRD.2010.04.0055

7. Brokaw EB, Murray T, Nef T, Lum PS. Retraining of interjoint arm coordination after stroke using robotassisted time-independent functional training. J Rehabil Res Dev. 2011;48(4):299-316. DOI:10.1682/JRRD.2010.04.0064

8. Acosta AM, Dewald HA, Dewald JPA. Pilot study to test effectiveness of video game on reaching performance in stroke. J Rehabil Res Dev. 2011;48(4):431-44. DOI:10.1682/JRRD.2010.04.0052

9. Koenig A, Omlin X, Zimmerli L, Sapa M, Krewer C, Bolliger M, Müller F, Riener R. Psychological state estimation from physiological recordings during robotassisted gait rehabilitation. J Rehabil Res Dev. 2011; 48(4):367-86. DOI:10.1682/JRRD.2010.03.0044

10. Masiero S, Armani M, Rosati G. Upper-limb robotassisted therapy in rehabilitation of acute stroke patients: Focused review and results of new randomized controlled trial. J Rehabil Res Dev. 2011;48(4):355-66. DOI:10.1682/JRRD.2010.04.0063

11. Burgar CG, Lum PS, Scremin AME, Garber SL, Van der Loos HFM, Kenney D, Shor P. Robot-assisted upper-limb therapy in acute rehabilitation setting following stroke: Department of Veterans Affairs multisite clinical trial. J Rehabil Res Dev. 2011;48(4):445-58. DOI:10.1682/JRRD.2010.04.0062
12. Scott SH, Dukelow SP. Potential of robots as nextgeneration technology for clinical assessment of neurological disorders and upper-limb therapy. J Rehabil Res Dev. 2011;48(4):335-54. DOI:10.1682/JRRD.2010.04.0057

13. Peng Q, Park HS, Shah P, Wilson N, Ren Y, Wu YN, Liu J, Gaebler-Spira DJ, Zhang LQ. Quantitative evaluations of ankle spasticity and stiffness in neurological disorders using manual spasticity evaluator. J Rehabil Res Dev. 2011;48(4):473-82. DOI:10.1682/JRRD.2010.04.0053

14. Roy A, Forrester LW, Macko RF. Short-term ankle motor performance with ankle robotics training in chronic hemiparetic stroke. J Rehabil Res Dev. 2011; 48(4):417-30. DOI:10.1682/JRRD.2010.04.0078

15. Shorter KA, Kogler GF, Loth E, Durfee WK, HsiaoWecksler ET. A portable powered ankle-foot orthosis for rehabilitation. J Rehabil Res Dev. 2011;48(4): 459-72. DOI:10.1682/JRRD.2010.04.0054

16. Perry JC, Oblak J, Jung JH, Cikajlo I, Veneman JF, Goljar N, Bizovičar N, Matjačić Z, Keller T. Variable structure pantograph mechanism with spring suspension system for comprehensive upper-limb haptic movement training. J Rehabil Res Dev. 2011;48(4): 317-34. DOI:10.1682/JRRD.2010.03.0043

17. Wier LM, Hatcher MS, Triche EW, Lo AC. Effect of robotic-assisted versus conventional body-weightsupported treadmill training on quality of life for people with multiple sclerosis. J Rehabil Res Dev. 2011; 48(4):483-92. DOI:10.1682/JRRD.2010.03.0035

This article and any supplementary material should be cited as follows:

Hidler J, Lum PS. The road ahead for rehabilitation robotics. J Rehabil Res Dev. 2011;48(4):vii-x.

DOI:10.1682/JRRD.2011.02.0014

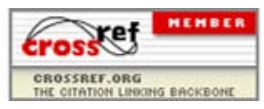

